\title{
Study on Engineering Design and Cost Performance of Borehole Heat Exchangers
}

\author{
Lei Yu and Jiemin Cheng \\ College of Population, Resources and Environment, Shandong Normal University, Jinan 250014, China \\ Correspondence should be addressed to Jiemin Cheng; jieminchengsdnu@163.com
}

Received 13 June 2015; Revised 14 August 2015; Accepted 27 August 2015

Academic Editor: Nader Karimi

Copyright ( 2015 L. Yu and J. Cheng. This is an open access article distributed under the Creative Commons Attribution License, which permits unrestricted use, distribution, and reproduction in any medium, provided the original work is properly cited.

\begin{abstract}
The ground source heat pump (GSHP) is an environmentally friendly and energy-efficient technology, and the investigations on the simulation models of borehole heat exchanger (BHE) have made progress. However, the researches on engineering design and economic performance based on the simulation models of BHE are a few. This paper firstly describes the interior and exterior heat transfer according to the existing achievements, and the corresponding characteristics of models are explained. Afterwards, the detailed design procedures of BHE size are provided and the cost performance is highlighted. Accordingly, an actual engineering project which employs GSHP system as the air conditioning system is researched; the necessary expenses on BHE, heat pump units, and indoor end equipment are all taken into account. The initial investment, operating cost, and other factors that exert influences on the cost performance are demonstrated. In addition, comparisons between different systems are conducted to show the advantages of GSHP. By means of thermal transfer analysis and the design of engineering project, the practicability, energy saving, and environmental protection of GSHP are brought into play, which means the promotion of this technology is the general trend of development of air condition system.
\end{abstract}

\section{Introduction}

The ground source heat pump (GSHP) system is the most advanced green air-conditioning technology in the world, because GSHP is favorable to achieve environmental protection and energy-saving. The underground low-grade energy is utilized with the help of heat pump unit and therefore the heating, cooling, and domestic hot water of buildings are all achieved [1]. More specifically, the thermal transfer is conducted from the circulating liquid of the heat exchange tube to the underground medium, which means the renewable energy existing in underground space can be made use of. Underground mediums locating at the depth of more than ten meters keep nearly constant temperature all the year round because they are free of the thermal disturbance that comes from the outside environment. The depth of underground mediums can achieve one hundred meters while GSHP is employed. Underground temperatures are lower and higher than outdoor air's temperatures in summer and in winter, respectively $[2,3]$. Therefore, the technical barriers such as frosting that appears at air source heat pump can be overcome and then the system efficiency is improved significantly. For example, the $4 \mathrm{~kW}$ heat quantity is acquired if only $1 \mathrm{~kW}$ electric energy is consumed; accordingly, the energy efficiency ratio is larger than 4. In addition, GSHP that employs borehole heat exchanger (BHE) as the underground heat transfer elements does not extract groundwater and thus the system is a new energy-saving technology keeping sustainable development. The whole system usually consists of several parts including BHEs, the heat pump unit, and end equipment, and sometimes domestic hot water is contained either.

Also, the advantages of GSHP should be followed with interest and they are summarized as several aspects. Firstly, high-efficiency and energy-saving are undeniable because running efficiency of GSHP is 30 50\% larger than that of traditional air-conditioning system. Secondly, there is no boiler and the corresponding room and therefore the problems of both air pollution and greenhouse gases emission are prevented. Thirdly, an equipment can serve several purposes. Next, the objectives of beautifying building and household metering are both realized when the GSHP is adopted in buildings. Last but not least, the characteristics of the safety 


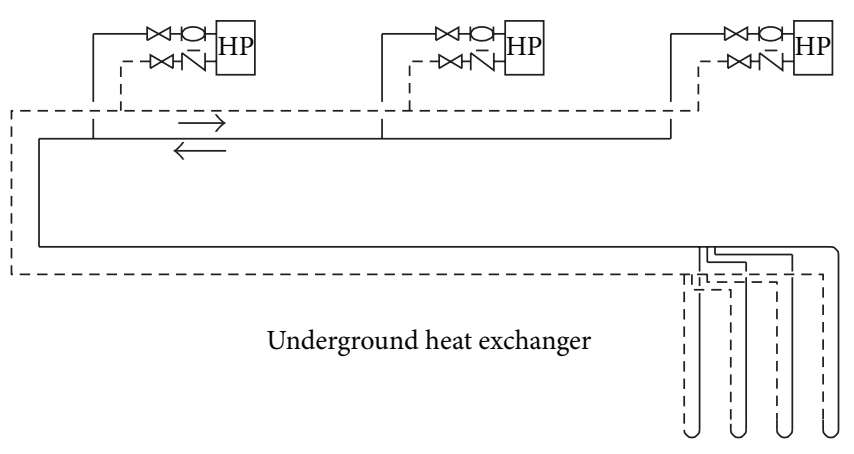

FIGURE 1: The schematic diagram of underground heat exchanger employed for cooling or heating.

and reliability should be emphasized as the life spans of BHE and heat pump unit, respectively, attain 50 and 20 years. Figure 1 shows the schematic diagram of BHEs that are responsible for the heat or cooling load of the building [4].

It can be observed that the underground heat transfer components of one engineering project are composed of a number of BHEs. No matter whether to study the theoretical models or to analyze the reasonable design of GSHP system, it is related to the BHEs.

The simulation models describing the heat transfer inside and outside borehole have gained more and more attention, and they have been put to use in theoretical calculation or engineering design. Apart from that, the design procedures of obtaining the BHE's reasonable size are becoming increasingly applicable. It is a pity that the analyses on engineering projects based on both thermal transmission models and design procedures are a few, and this is a noticeable research gap. The novelty and originality of the paper are to investigate design procedure and cost performance of engineering projects according to the heat transfer simulation models. Afterwards, the detailed design plane for an actual project is conducted to certify the necessity of applying GSHP system; the comparison between GSHP and other systems is made to show the significant economic performance of GSHP system.

\section{Simulation Models of Heat Transfer}

2.1. Heat Transfer Inside Borehole GHE. Borehole is drilled and then the U-tubes are installed into it [5]. The vertical BHE is produced if the backfilling materials are poured, and these materials have the effects of sealing and improving heat transfer performance. The heat transfer domain from U-tube to underground medium is divided into two parts, that is, the areas inside and outside borehole [6]. The steady-state mode can be put into use to deal with the heat exchange inside GHE because the geometric size and thermal capacity are relatively small compared with those outside borehole. The equivalent diameter is employed to simplify the model and it is usually applied to explore the heat transfer between U-tube and the borehole wall [7]; the principle is that all branch pipes are simplified as a pipe with larger diameter; therefore, the twodimensional conduction can be regarded as a one-dimension radial heat exchange.
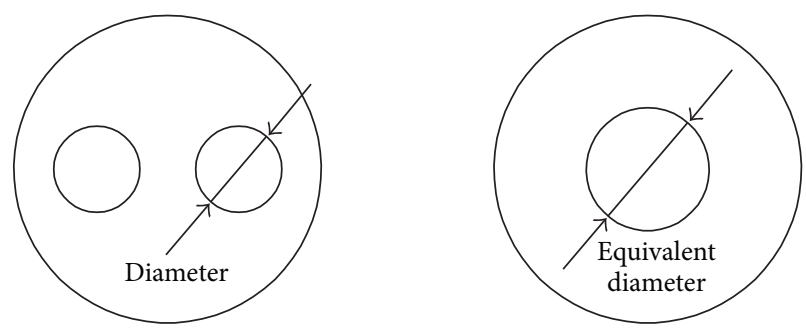

FIGURE 2: The diameter and the corresponding equivalent diameter of U-tube.

The heat conductivities of backfilling material, pipe material, and underground medium are, respectively, $k_{b}, k_{p}$, and $k_{s}$. The radius of borehole, external radius of pipe, and inner radius of pipe are, respectively, $r_{b}, r_{0}$, and $r_{i}$. The layout drawing of $U$-tube inside borehole and the corresponding equivalent diameter are both shown in Figure 2.

The equivalent diameter of U-tubes is approximately $\sqrt{n} d_{0}$ in case the number of branch tubes is $n$; thus, the thermal-convection resistance from the circulating fluid to the inner wall of tube is expressed in (1) while the convection coefficient is $h$ :

$$
R_{f}=\frac{1}{2 \pi r_{i} h}
$$

Then, the thermal resistance between inner wall and external wall of tube is concluded in

$$
R_{t}=\frac{1}{2 \pi k_{p}} \ln \frac{\sqrt{n} r_{0}}{\sqrt{n} r_{0}-\left(r_{0}-r_{i}\right)} .
$$

Afterwards, the heat is further conveyed to the borehole wall when the backfilling material acts as the thermal conductor, and the corresponding resistance is shown in

$$
R_{b}=\frac{1}{2 \pi k_{b}} \ln \frac{r_{b}}{\sqrt{n} r_{0}} .
$$

The total resistance inside borehole should be summarized according to the analyses above, and the expression of energy equation is given in (4) while the temperatures of circulating liquid and the borehole wall are, respectively, $t_{f}$ and $t_{b}$. There is no doubt that the parameters such as driving force of heat transfer, thermal resistance and heat flux are shown clearly. Three components constitute the total resistance inside $\mathrm{BHE}$, and the original source of heat energy is the circulating liquid. $q_{l}$ is the heat transfer rate of BHE, that is, the heat transfer quantity per meter BHE:

$$
t_{f}-t_{b}=\left(R_{f}+R_{t}+R_{b}\right) q_{l} .
$$

\subsection{Heat Transfer Outside Borehole GHE}

2.2.1. Line Heat Source Model. Obviously, the heat continues to be transmitted to far locations of underground medium. The heat transfer process outside BHE plays a significant role in carrying energy, because the borehole's diameter is 


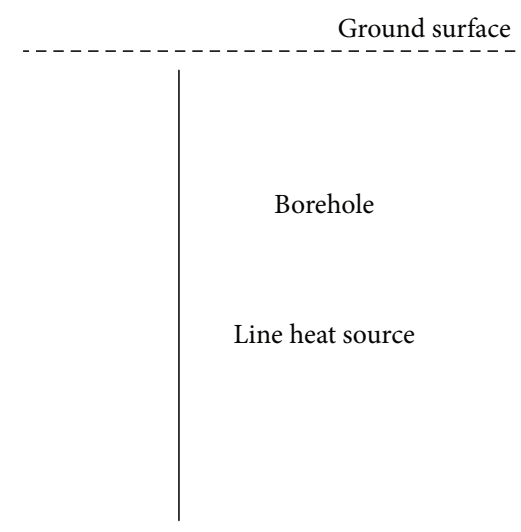

FIGURE 3: The line heat source adopted for BHE.

so small that the heat capacity inside BHE is little and the thermal resistance outside borehole is much larger than that inside borehole. The investigation on heat transfer outside borehole is becoming increasingly important and therefore the reasonable mathematical simulation models should be taken into account. The borehole's depth is far larger than its diameter and thus BHE can be regarded as a line heat source [8], which means the radius of BHE is ignored when the heat transfer outside borehole is studied. The diagram of line heat source is described in Figure 3.

Accordingly, a most widely used one-dimensional model for this purpose is Kelvin's line source model, in which the borehole is replaced by a line heat source with its radial dimension neglected. However, the actual depth of any BHE is finite and then the finite line heat source is proposed; the Kelvin's model lays a firm foundation for the research of the finite line heat source [9]. In order to investigate the conduction around the borehole, Green's function theory is employed and the corresponding expression is given in (5) showing the temperature response of any point $(x, y, z)$ except heat source in the underground medium at time $\tau$, and the point heat source locating at $\left(x^{\prime}, y^{\prime}, z^{\prime}\right)$ emits heat at time $\tau^{\prime}[10]$ :

$$
\begin{gathered}
G\left(x, y, z, \tau ; x^{\prime}, y^{\prime}, z^{\prime}, \tau^{\prime}\right)=\frac{1}{8\left[\pi a\left(\tau-\tau^{\prime}\right)\right]^{3 / 2}} \\
\cdot \exp \left\{-\frac{\left(x-x^{\prime}\right)^{2}+\left(y-y^{\prime}\right)^{2}+\left(z-z^{\prime}\right)^{2}}{4 a\left(\tau-\tau^{\prime}\right)}\right\} .
\end{gathered}
$$

After that, the temperature response induced by the finite line heat source is obtained in (6), where erfc is the complementary error function and $t_{0}$ is the initial temperature of the underground medium [11]:

$$
\begin{aligned}
& t-t_{0}=\frac{q_{l}}{4 \pi k} \\
& \cdot \int_{0}^{H}\left\{\frac{\operatorname{erfc}\left[\sqrt{\left(x-x^{\prime}\right)^{2}+\left(y-y^{\prime}\right)^{2}+\left(z-z^{\prime}\right)^{2}} / 2 \sqrt{a \tau}\right]}{\sqrt{\left(x-x^{\prime}\right)^{2}+\left(y-y^{\prime}\right)^{2}+\left(z-z^{\prime}\right)^{2}}}\right. \\
&\left.-\frac{\operatorname{erfc}\left[\sqrt{\left(x-x^{\prime}\right)^{2}+\left(y-y^{\prime}\right)^{2}+\left(z-z^{\prime}\right)^{2}} / 2 \sqrt{a \tau}\right]}{\sqrt{\left(x-x^{\prime}\right)^{2}+\left(y-y^{\prime}\right)^{2}+\left(z+z^{\prime}\right)^{2}}}\right\} d z^{\prime} .
\end{aligned}
$$

To facilitate the expression, the nondimensional parameters are employed and the corresponding forms are $\Theta=$ $k\left(t-t_{0}\right) / q_{l}, X=x / r_{b}, Y=y / r_{b}, Z=z / r_{b}, X^{\prime}=x^{\prime} / r_{b}$, $Y^{\prime}=y^{\prime} / r_{b}, Z^{\prime}=z^{\prime} / r_{b}, H=h / r_{b}, F O=a \tau / r_{b}^{2}$. Equation (6) is translated into

$$
\begin{gathered}
\Theta=\frac{1}{4 \pi} \int_{0}^{H}\left\{\frac{\operatorname{erfc}\left[\sqrt{\left(X-X^{\prime}\right)^{2}+\left(Y-Y^{\prime}\right)^{2}+\left(Z-Z^{\prime}\right)^{2}} / 2 \sqrt{F o}\right]}{\sqrt{\left(X-X^{\prime}\right)^{2}+\left(Y-Y^{\prime}\right)^{2}+\left(Z-Z^{\prime}\right)^{2}}}\right. \\
\left.-\frac{\operatorname{erfc}\left[\sqrt{\left(X-X^{\prime}\right)^{2}+\left(Y-Y^{\prime}\right)^{2}+\left(Z+Z^{\prime}\right)^{2}} / 2 \sqrt{F o}\right]}{\sqrt{\left(X-X^{\prime}\right)^{2}+\left(Y-Y^{\prime}\right)^{2}+\left(Z+Z^{\prime}\right)^{2}}}\right\} d Z^{\prime} .
\end{gathered}
$$

The temperature responses with the time are shown in Figure 4 according to the calculation results of (7).

It is found that all the temperature responses will be stable at last. Furthermore, the larger the length, the fiercer the response.

2.2.2. Cylindrical Heat Source Model. The heat capacity inside borehole can be ignored as the diameter is extremely small compared to its depth, but the existence of inner heat transfer is undisputed. Accordingly, the line heat source model is not an ideal choice for simulating the heat transfer of BHE. The solid cylindrical heat sources have been proposed in recent years; in this model, it is supposed that the cylinder is no longer a cavity but is filled with the medium identical to that out of the cylinder [12-14]. The whole infinite domain is composed of a homogeneous medium and therefore the heat capacity of borehole is taken into consideration. The diagram of cylindrical heat source is shown in Figure 5.

The Green function is still the basic method to obtain the temperature response caused by the heat source, and 


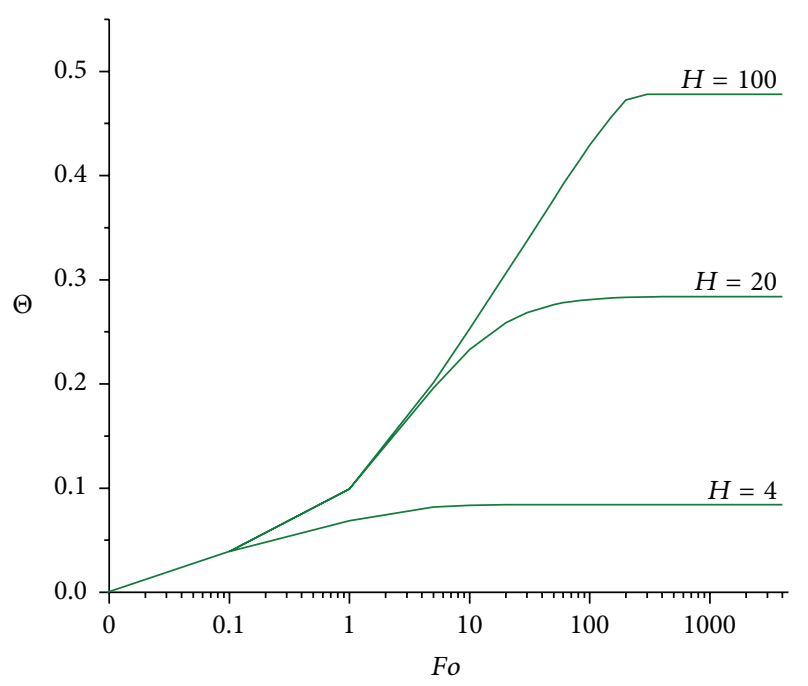

FIGURE 4: The temperature responses of finite line heat source with the time.

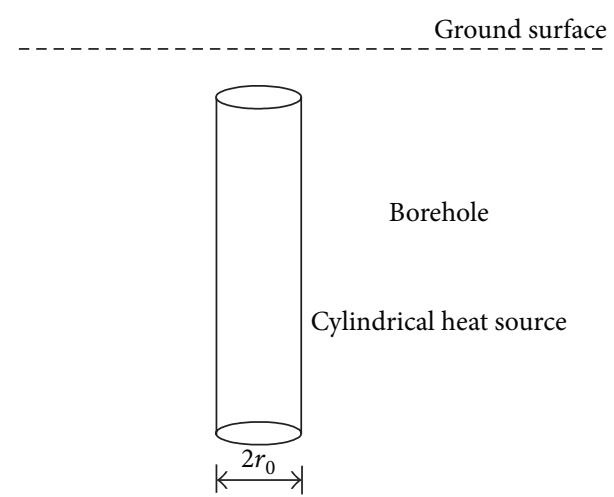

FIGURE 5: The cylindrical heat source adopted for BHE.

the temperature response of any point in the underground medium except heat source is shown in

$$
\begin{aligned}
& t-t_{0}=\frac{q_{l}}{8 \pi k} \int_{0}^{\tau} \frac{1}{\left(\tau-\tau^{\prime}\right)} I_{0}\left[\frac{\sqrt{x^{2}+y^{2}} r_{b}}{2 a\left(\tau-\tau^{\prime}\right)}\right] \\
& \cdot \exp \left[-\frac{\sqrt{x^{2}+y^{2}}+r_{b}^{2}}{4 a\left(\tau-\tau^{\prime}\right)}\right] \cdot\left\{\operatorname{erfc}\left[\frac{z-H}{2 \sqrt{a\left(\tau-\tau^{\prime}\right)}}\right]\right. \\
& +\operatorname{erfc}\left[\frac{z+H}{2 \sqrt{a\left(\tau-\tau^{\prime}\right)}}\right] \\
& \left.-2 \operatorname{erfc}\left[\frac{z}{2 \sqrt{a\left(\tau-\tau^{\prime}\right)}}\right]\right\} d \tau^{\prime},
\end{aligned}
$$

where $I_{0}$ is the zero-order modified Bessel function and the borehole is supposed to be arranged at $z$-axis. Again,

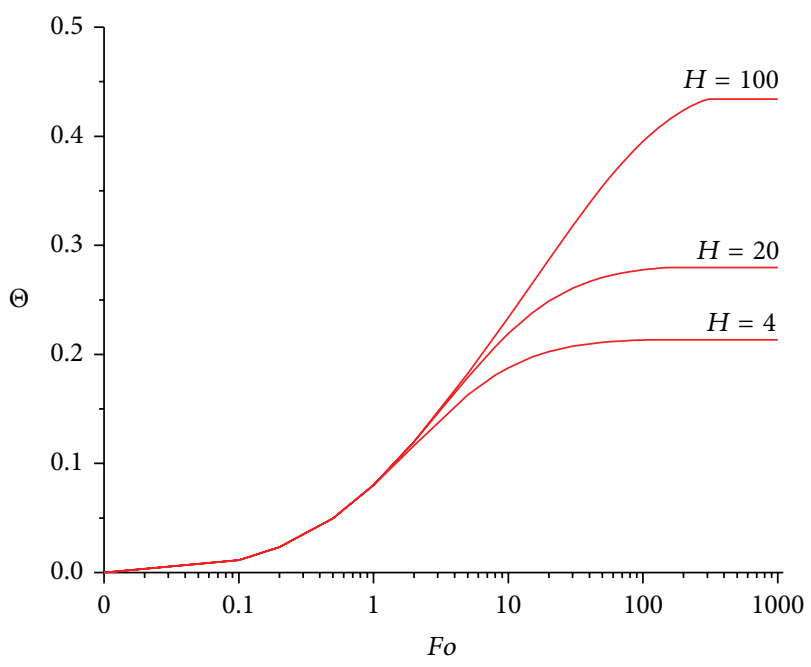

FIGURE 6: The temperature responses of cylindrical heat source with the time.

dimensionless method is used to simplify the expression and the corresponding formula is given in

$$
\begin{aligned}
\Theta & =\frac{1}{8 \pi} \int_{0}^{F o} \frac{d F o^{\prime}}{\left(F o-F o^{\prime}\right)} I_{0}\left[\frac{\sqrt{X^{2}+Y^{2}}}{2\left(F o-F o^{\prime}\right)}\right] \\
& \cdot \exp \left[-\frac{X^{2}+Y^{2}+1}{4\left(F o-F o^{\prime}\right)}\right] \cdot\left\{\operatorname{erfc}\left[\frac{Z-H}{2 \sqrt{F o-F o^{\prime}}}\right]\right. \\
& \left.+\operatorname{erfc}\left[\frac{Z+H}{2 \sqrt{F o-F o^{\prime}}}\right]-2 \operatorname{erfc}\left[\frac{Z}{2 \sqrt{F o-F o^{\prime}}}\right]\right\} .
\end{aligned}
$$

The temperature responses with the time are shown in Figure 6, and the regular patterns and trends are similar with those of line heat source; that is, all responses must attain the steady states and the response value increase with the borehole length if the time is constant.

As far as the differences between line and cylindrical sources are concerned, the temperature responses changing with time are described in Figure 7 when the radius and depth of borehole are constant.

It is noticed that the temperature response of cylindrical heat source is always larger than that of line heat source. The dimensionless temperature response is $\Theta=k\left(t-t_{0}\right) / q_{l}$, and the heat transfer rate of line heat source becomes larger while the actual temperature rise is stable. Therefore, the calculational length of BHEs by means of line heat source is shorter than that depending on cylindrical heat source when the design of BHEs is conducted.

\section{The Validation of Heat Transfer Experiments}

Line and cylindrical heat source models are usually adopted to simulate the heat transfer of $\mathrm{BHE}$, and their rationalities can be validated by means of experiments. A hot water tank with electronic heater is employed and the power 


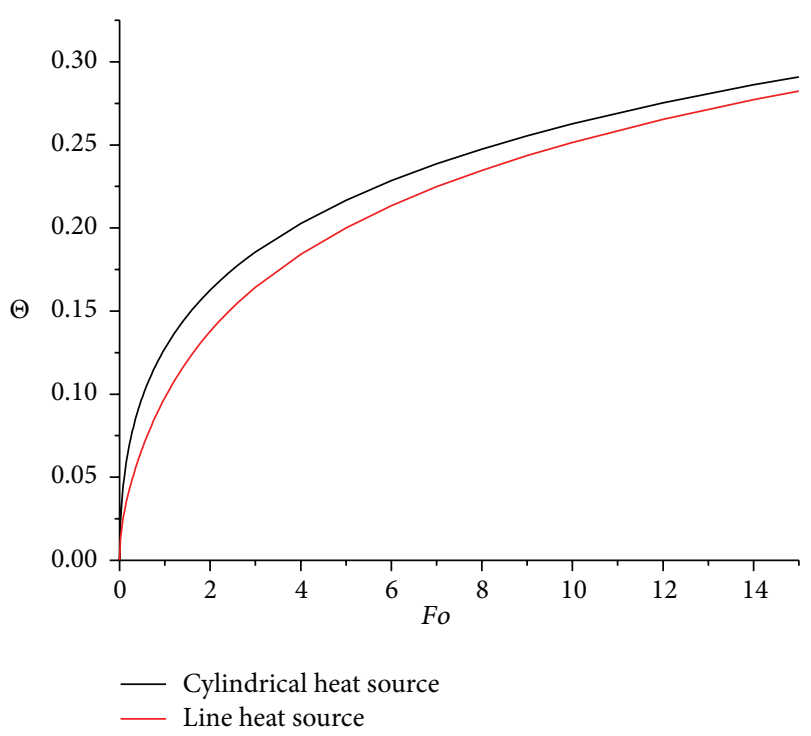

Figure 7: The comparison of temperature responses between line and cylindrical heat sources.

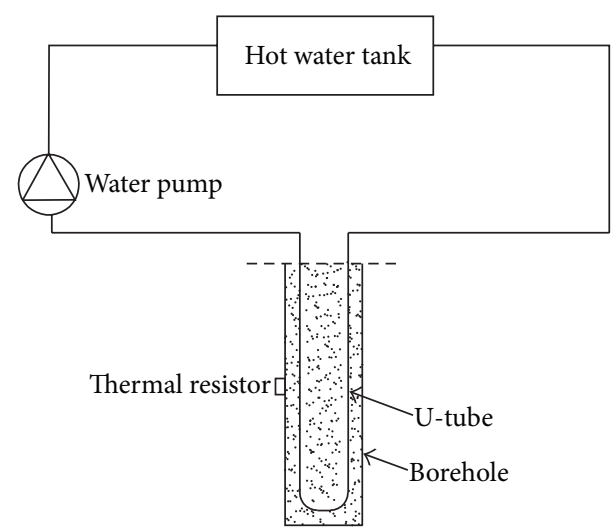

FIGURE 8: Diagram of experiment of temperature response.

of tank is constant in the process of experiment. Figure 8 shows the diagram of experiment and the BHE with $\mathrm{U}$ tube is used. The circulating fluid enters the tank and is heated by electronic heater and then flows through the $\mathrm{U}$ tube of borehole to exchange heat with the underground medium. The water pump drives the circulating liquid to flow circularly. Thermal sensors are set at the surface of borehole to record the temperature response with the time. The initial temperature and thermophysical properties of underground medium are known before conducting the experiment. In addition, the inlet and outlet temperatures of circulating liquid are recorded to calculate the heat transfer rate $q_{l}$. There are three sensors, one is set at the depth's middle location of the outer surface of borehole, the other two are employed to record the inlet and outlet temperatures of circulating liquid, and the accuracy of thermal sensors is $\pm 0.1 \%$. The diameter of BHE is $130 \mathrm{~mm}$ and the flow rate of fluid is around 0.3 liters/s.

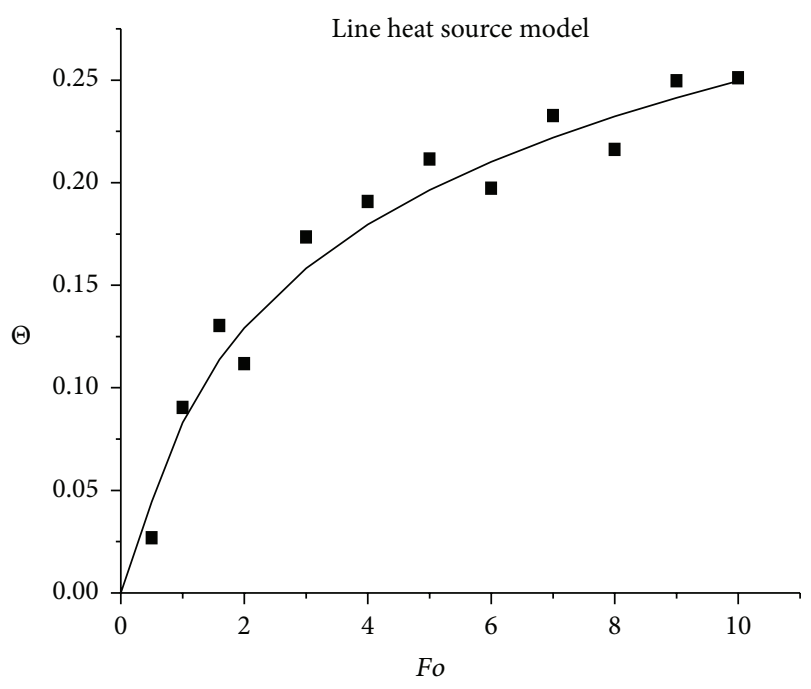

(a)

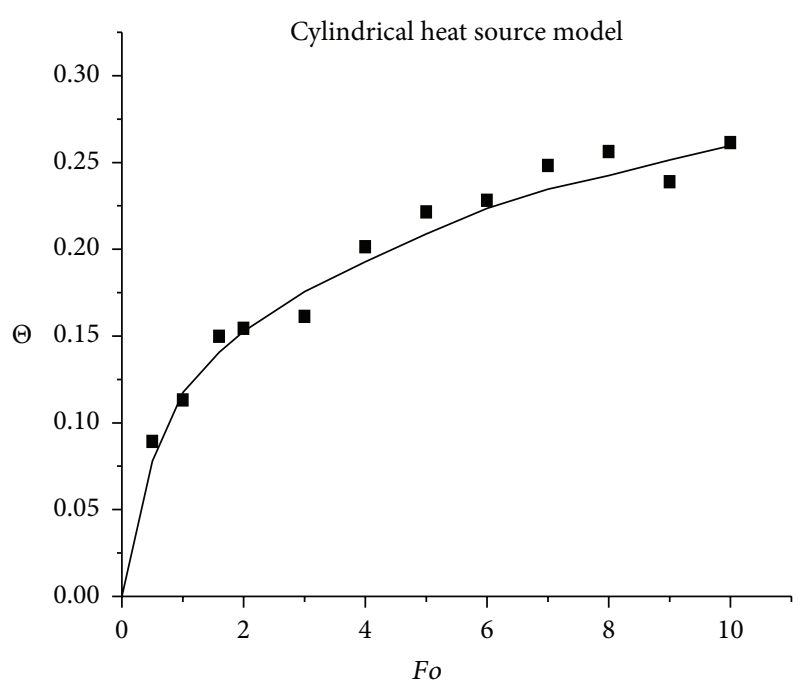

(b)

FIGURE 9: The comparisons between theoretical results and experimental data.

$\Theta=k\left(t-t_{0}\right) / q_{l}$, and the dimensionless temperature response can be obtained based on the actual temperature recorded by the thermal sensor with the time. Then, the theoretical dimensional temperature responses of line and cylindrical heat sources can be obtained according to (7) and (9), respectively. Accordingly, the comparisons between experimental data and simulation results are shown in Figure 9.

The linear graph stands for the calculation results by means of simulation models and the scattergram means the experimental data. It is found that the deviation between theoretical result and experimental value is smaller if the cylindrical heat source model is employed; this is because the inner heat capacity of BHE is considered. As a result, cylindrical heat source model is more reasonable for the study of the engineering design or cost performance. 


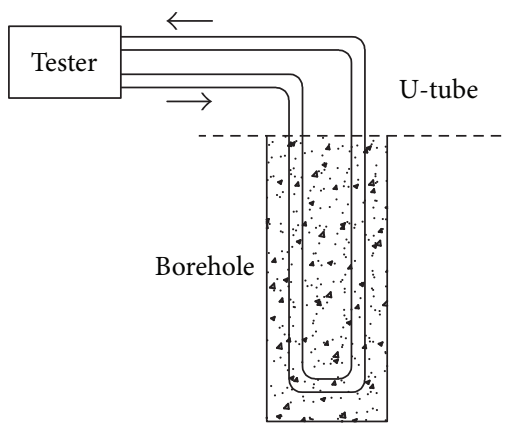

FIGURE 10: The equipment recording the parameters of circulating liquid.

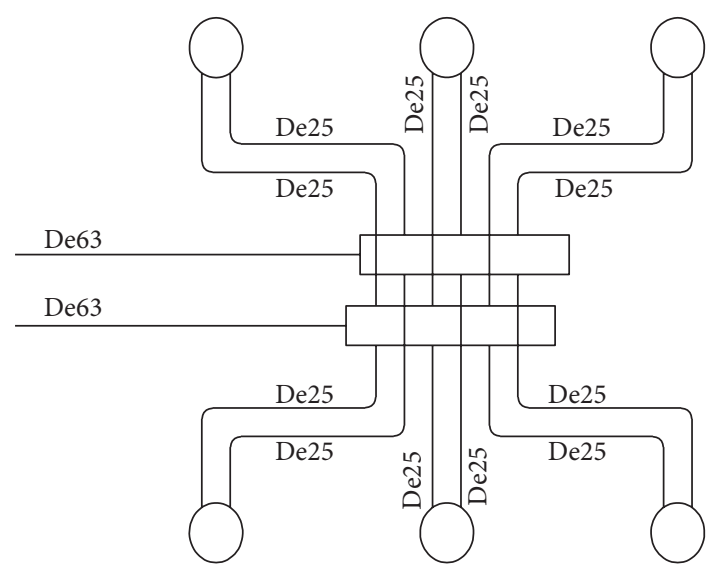

FIGURE 11: The connection of a group of BHEs.

\section{The Engineering Design for Borehole GHEs}

Section 2 presents the necessary theoretical knowledge of simulating heat transfer of $\mathrm{BHE}$, and these contents illustrate the fundamental principles of heat transfer of BHE. There is no doubt that engineering design can put this technology into practice, and the significant design procedures and the corresponding design parameters should be emphasized to optimize the whole system. There are a number of considerations that need to be studied and they are listed in the following.

4.1. The Test of Thermal Property of Underground Medium. The thermal physical properties are very important because they can be used to calculate the size of $\mathrm{BHE}$, and the field measurement combined with parameters estimation is employed to obtain the actual thermal physical parameters [15]. The on-site measuring devices connected with U-tube are shown in Figure 10.

The object function reporting the sum of variance is established and the expression is given in

$$
f=\sum_{i=1}^{n}\left(T_{\mathrm{cal}, i}-T_{\mathrm{exp}, i}\right),
$$

TABLE 1: The areas and corresponding loads.

\begin{tabular}{lcccc}
\hline $\begin{array}{l}\text { Building } \\
\text { nature }\end{array}$ & $\begin{array}{c}\text { Building } \\
\text { area } \\
\left(\mathrm{m}^{2}\right)\end{array}$ & $\begin{array}{c}\text { Air- } \\
\text { conditioning } \\
\text { area } \\
\left(\mathrm{m}^{2}\right)\end{array}$ & $\begin{array}{c}\text { Cooling } \\
\text { load } \\
(\mathrm{kW})\end{array}$ & $\begin{array}{c}\text { Heating } \\
\text { load } \\
(\mathrm{kW})\end{array}$ \\
\hline Library & 26800 & 21300 & 2378 & 2308 \\
\hline
\end{tabular}

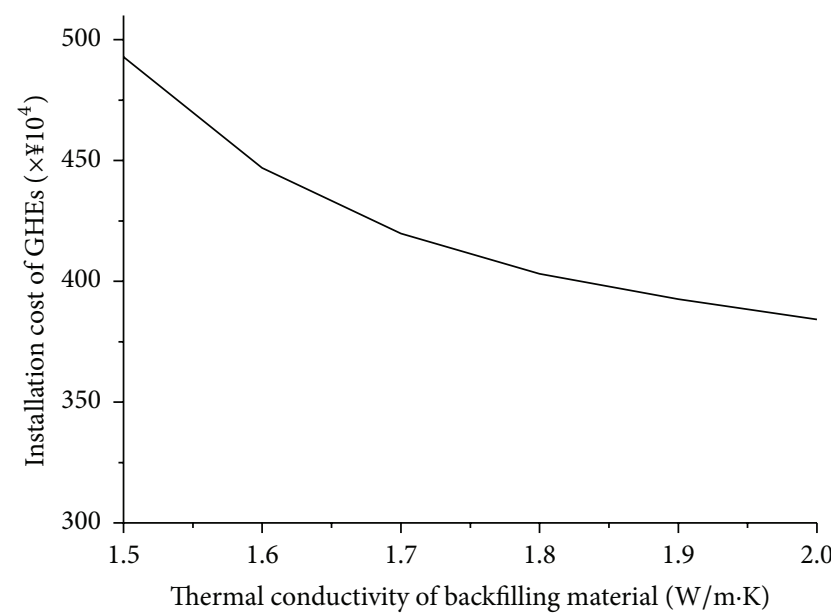

FIGURE 12: The installation cost of GHEs changes with the thermal conductivity of backfilling material.

where $T_{\mathrm{cal}, i}$ and $T_{\exp , i}$ are, respectively, the circulating liquid's average temperatures of mathematical model and experimental recorded data [16]. Because the parameters of thermal physical parameters of underground medium are contained in the simulation model, the value of thermal physical parameters can be obtained by means of reverse calculation method while the value of $f$ achieves the minimum.

4.2. The Cooling and Heat Load Assumed by UHEs. The heat of the building is abstracted and then is discharged into underground in summer, thereby the maximal heat release appears at the time of the maximal cooling load of buildings. The expression of the heat release is the maximal cooling load $\times(1+1 / \mathrm{COP})$, where COP is the coefficient of performance of the heat pump unit.

In winter, the ultimate value of heat absorption occurs while the heat load of buildings reaches the maximum, and the corresponding formula is the maximal heating load $\times(1-$ $1 / \mathrm{COP})$, where COP means the heating performance coefficient. Comparing the heat release with the heat absorption, the final total length of $\mathrm{BHE}$ is determined according to the large one.

4.3. The Calculation of Pressure Drop. The purpose of calculating pressure drop is to choose the water pump so that the liquid can achieve circulation flow. As far as the BHEs are concerned, to obtain the linear head loss and partial resistance is the basis of determining the circulating pump. $W, A$, and $d$ are, respectively, the rate of flow, area of cross 
TABLE 2: Parameters of the heat pump unit of GSHP system.

\begin{tabular}{lcccccc}
\hline $\begin{array}{l}\text { Operating } \\
\text { mode }\end{array}$ & $\begin{array}{c}\text { Cooling/heating } \\
\text { capacity } \\
(\mathrm{kW})\end{array}$ & $\begin{array}{c}\text { Temperature of } \\
\text { U-tube circulating } \\
\text { liquid } \\
\left({ }^{\circ} \mathrm{C}\right)\end{array}$ & $\begin{array}{c}\text { Temperature of } \\
\text { cooling water } \\
\left({ }^{\circ} \mathrm{C}\right)\end{array}$ & $\begin{array}{c}\text { Pressure drop of } \\
\text { evaporator } \\
(\mathrm{kPa})\end{array}$ & $\begin{array}{c}\text { Pressure drop of } \\
\text { condenser } \\
(\mathrm{kPa})\end{array}$ & $\begin{array}{c}\text { Electricity } \\
\text { consumption } \\
(\mathrm{kW})\end{array}$ \\
\hline Cooling & 1130 & $12 / 7$ & $15 / 23$ & 98 & 13.7 & 193 \\
Heating & 1473 & $50 / 45$ & $15 / 10$ & 98 & 13.7 & 336 \\
\hline
\end{tabular}

section, and inner diameter of tube; therefore, the velocity $V$ is obtained according to

$$
V=\frac{W}{3600 \times A}=\frac{4 W}{3600 \times \pi \times d^{2}} .
$$

Because the turbulence is prerequisite while the liquid flows during the running process, the corresponding Reynolds number, that is, Re, should be larger than 2300 to ensure this state. The expression of Re is shown in

$$
\operatorname{Re}=\frac{\rho V d}{\mu},
$$

where $\rho$ and $\mu$ are, respectively, the density and coefficient of liquid's dynamic viscosity and the calculation of Re is significant before studying the head loss. Next, (13) offers the linear heat loss and it involves several parameters:

$$
P_{L}=0.158 \times \rho^{0.75} \times \mu^{0.25} \times d^{1.25} \times V^{1.75} \times L,
$$

where $L$ denotes the length of tube of liquid.

Partial loss usually occurs when fluid flows through the elbows, equipment, and so on, and (14) shows the detailed expression

$$
P_{p}=0.158 \times \rho^{0.75} \times \mu^{0.25} \times d^{1.25} \times V^{1.75} \times E,
$$

where $E$ means the equivalent length of the elbows, equipment, and so on.

Afterwards, the total pressure drop is equal to the sum of linear head loss and partial loss [17, 18].

4.4. The Joining of BHEs. It is unquestionable that there are a number of BHEs for engineering project, which means BHEs are distributed row after row or column after column; the connection of BHEs is a technology that importance should be attached to. The subcatchment devices are commonly employed to connect a group of BHEs and there are many groups. Then, all distributors are linked to the room of heat pump. The liquids of a group of BHEs are connected by collecting breeching and then enters the room of heat pump. Later, the liquid returns and then is distributed by the separator to flow through tubes of boreholes in parallel. The material of $U$-tube is high-density polyethylene and this material has favorable conductivity, corrosion resistance, and long service life. The diagram describing the connection of a group of BHEs is shown in Figure 11.

As a rule, the external diameter of every U-tube is usually $25 \mathrm{~mm}$ or $32 \mathrm{~mm}$, and the HDPE tubes which have the external diameter of $50 \mathrm{~mm}$ or $63 \mathrm{~mm}$ are often used as the main tube of a group of BHEs.
4.5. The Backfilling Material inside Borehole. Backfilling material lies in the area between U-tube and borehole wall, and it enhances the heat transfer and stops the surface water from groundwater permeation. The reasonable backfilling material guarantees the heat transfer performance of BHEs. The heat resistance inside borehole is inevitably increased in case the backfilling material has undesirable conduction performance; therefore, the total lengths of BHEs are lengthened and both investment and operating costs are added. Researchers have paid more and more attention to the improvement of backfilling material with the development of GSHP technology.

The main characteristics of backfilling material consist of conduction coefficient, uniformity, stability, and antihot pressing [19-21]. Cement, sand, and bentonite are usually employed to compose the material and the corresponding conduction performance depends on the ratios of these elements. The overseas research indicated that the heat conductivity can arrive at $2.0 \mathrm{~W} /(\mathrm{m} \cdot \mathrm{K})$, and in recent years the civil experts or scholars found that the value can be further improved and even achieved $2.1 \mathrm{~W} /(\mathrm{m} \cdot \mathrm{K})$ [22]. The influence that backfilling material exerts on the length of BHEs is obvious even if the value of heat conductivity is increased a little.

\section{The Analysis on the Actual Projects of GSHP System}

Although Sections 2 and 3, respectively, present the theoretical simulation models and engineering design of BHEs, the practicability, economical efficiency, and energy-saving of GSHP technology should be validated by actual engineering projects.

5.1. The Project Information. This building is a library and it belongs to public construction, the floor and air-conditioning areas are, respectively, $26800 \mathrm{~m}^{2}$ and $21300 \mathrm{~m}^{2}$, and the height is nearly $30 \mathrm{~m}$. Table 1 lists the information of the areas and air-conditioning loads.

5.2. The First Design Plan. Both cooling and heat loads are assumed by BHEs so that the unity of cold and heat sources is achieved. There are two heat pump units that are responsible for cooling and heating and the corresponding parameters are given in Table 2.

The total length of BHEs is $36640 \mathrm{~m}$ according to the analysis and calculation; there are 458 boreholes with 


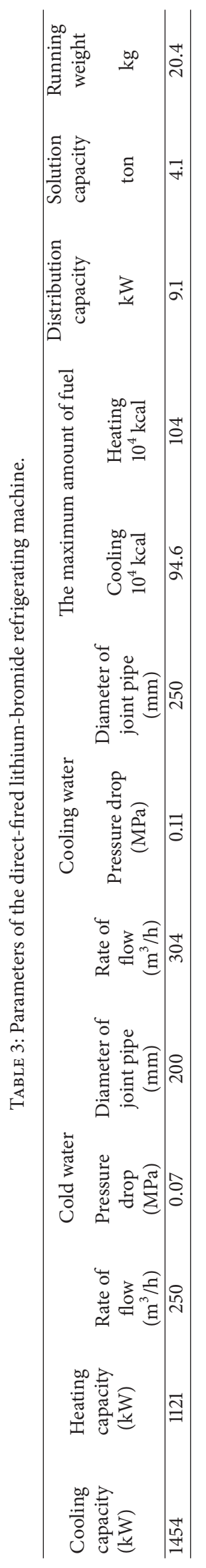


TABLE 4: Initial cost of GSHP system.

\begin{tabular}{|c|c|c|c|}
\hline Equipment & Number & $\begin{array}{l}\text { Unit price } \\
\quad\left(¥ 10^{4}\right)\end{array}$ & $\begin{array}{l}\text { Sum price } \\
\quad\left(¥ 10^{4}\right)\end{array}$ \\
\hline Heat pump units & 2 & 119.365 & 238.73 \\
\hline Cold water pump & 2 & 1.55 & 3.1 \\
\hline Cooling water pump & 2 & 1.55 & 3.1 \\
\hline $\begin{array}{l}\text { Water separator } \\
\text { (outdoor circulation) }\end{array}$ & 1 & 0.98 & 0.98 \\
\hline $\begin{array}{l}\text { Water collector } \\
\text { (outdoor circulation) }\end{array}$ & 1 & 0.98 & 0.98 \\
\hline $\begin{array}{l}\text { Barrier diaphragm-type } \\
\text { pressurized water tank }\end{array}$ & 1 & 0.69 & 0.69 \\
\hline Installation of UHEs & & & 492.85 \\
\hline Total & & & 740.43 \\
\hline
\end{tabular}

TABLE 5: Initial cost of the direct-fired lithium-bromide refrigerating machine system.

\begin{tabular}{lccc}
\hline Equipment & Number & $\begin{array}{c}\text { Unit price } \\
\left(¥ 10^{4}\right)\end{array}$ & $\begin{array}{c}\text { Sum price } \\
\left(¥ 10^{4}\right)\end{array}$ \\
\hline DFLBRM & 2 & 135 & 270 \\
\hline Cooling tower & 2 & 11.05 & 22.1 \\
\hline Cold water pump & 2 & 1.55 & 3.1 \\
\hline Cooling water pump & 2 & 1.55 & 3.1 \\
\hline Gas & 29779.9 & 0.0025 & 74.4498 \\
\hline Gas pipe laying work & & & 100 \\
\hline \multicolumn{3}{c}{ Total } \\
\hline
\end{tabular}

the diameter of $140 \mathrm{~mm}$ and every one has the depth of $80 \mathrm{~m}$, and the row and column intervals are both $4 \mathrm{~m}$.

5.3. The Second Design Plan. The direct-fired lithiumbromide refrigerating machine (DFLBRM) is employed for cooling and heating. The cooling tower is set in the open air to act as the heat discharge equipment for the cooling condition, and the gas is fired to become the driving heat source so that the heating objective is achieved. The characteristics of this plan can be summarized as several points: firstly, it can save electricity but not save energy; secondly, the cold and heat sources are united; thirdly, the requirements of the automatic control and safety are very high.

According to the cooling and heat loads, two DFLBRMs are selected and the corresponding parameters are listed in Table 3.

5.4. Comparisons of Costs between the Planes. Tables 4 and 5 , respectively, describe the investments of the first and the second design planes.

In this project, the thermal conductivity of backfilling material is $1.5 \mathrm{~W} /(\mathrm{m} \cdot \mathrm{K})$ and the corresponding installation cost of BHEs is $¥ 492.85 \times 10^{4}$. The thermal conductivity can exert influence on the cost, and the corresponding cost decreases with the increase of thermal conductivity, the detailed information is shown in Figure 12.
It should be admitted that the initial cost of GSHP is obviously higher than that of DFLBRMs, but the running cost of these two different modes can embody the advantage of GSHP technology. And the initial cost of GSHP can be further reduced while the thermal conductivity of backfilling material is increased, and the installation cost of BHEs is obtained according to the minimal value of conductivity. The detailed information of operating costs is shown in Tables 6 and 7.

The significant data of tables make clear that the initial cost of GSHP system is expensive; however, the favorable benefits in terms of energy-saving and environmental protection are certainly achieved [23]. In addition, the most attentiongetting point is that the running cost is obviously lower and the payback period is less than 4 years compared with the DFLBRMs. What is more, the installation cost of BHEs can be reduced while the thermal conductivity of backfilling material increases, and this can further improve the economic performance of the whole GSHP system.

\section{Conclusions}

The vertical BHEs are typical underground components that are in charge of heat release and heat abstraction; the paper demonstrates the fundamental principles of heat transfer inside and outside borehole. The research on theoretical knowledge lays a firm foundation for the engineering design of GSHP projects. The construction of underground installation is complicated and therefore a series of technological process are explained in detail, including steps and parameters. The discussions of theoretical heat transfer and actual engineering knowledge enable researchers to understand how to make full use of GSHP. In addition, an actual engineering project that employs GSHP system is analyzed; as far as GSHP and DFLBRMs are concerned, not only the investments but also the operating costs are compared with each other. By means of comparisons, it should be highlighted that the initial expense of GSHP is higher but the running cost is lower, which means the added part of initial cost can be saved by way of saving running cost. The initial cost of GSHP can be reduced further while the thermal conductivity of backfilling material is increased, and this can let the cost performance of GSHP be improved further. According to the detailed illustration, GSHP will make greater progress and gain more and more attention in the future.

\section{Conflict of Interests}

The authors declare that there is no conflict of interests regarding the publication of this paper.

\section{Acknowledgment}

The authors would like to thank the National Natural Science Fund Committee, China, for financial support (41171251). 
TABLE 6: Operating cost of GSHP system.

\begin{tabular}{|c|c|c|c|c|c|c|c|c|c|}
\hline Equipment & Number & $\begin{array}{c}\text { Electricity } \\
\text { consumption } \\
\text { kW }\end{array}$ & $\begin{array}{c}\text { Running } \\
\text { time } \\
\mathrm{h}\end{array}$ & $\begin{array}{c}\text { Energy } \\
\text { consumption } \\
\text { kWh }\end{array}$ & $\begin{array}{l}\text { Unit price } \\
¥ / \mathrm{kWh}\end{array}$ & $\begin{array}{c}\text { Operating } \\
\text { cost per day } \\
¥ 10^{4}\end{array}$ & $\begin{array}{c}\text { Operating } \\
\text { cost per } \\
\text { month } \\
¥ 10^{4}\end{array}$ & $\begin{array}{l}\text { Operat- } \\
\text { ing } \\
\text { months }\end{array}$ & $\begin{array}{c}\text { Operating } \\
\text { cost per year } \\
¥ 10^{4}\end{array}$ \\
\hline \multirow{2}{*}{$\begin{array}{l}\text { Heat pump } \\
\text { units }\end{array}$} & $\begin{array}{c}\text { Cooling } \\
2\end{array}$ & 193 & 12 & 4632 & 0.6 & 0.27792 & 8.3376 & 3 & 25.0128 \\
\hline & $\begin{array}{c}\text { Heating } \\
2\end{array}$ & 336 & 12 & 8064 & 0.6 & 0.48384 & 14.5152 & 4 & 58.0608 \\
\hline $\begin{array}{l}\text { Cold water } \\
\text { pump }\end{array}$ & 2 & 37 & 12 & 888 & 0.6 & 0.05328 & 1.5984 & 7 & 11.1888 \\
\hline $\begin{array}{l}\text { Cooling water } \\
\text { pump }\end{array}$ & 2 & 37 & 12 & 888 & 0.6 & 0.05328 & 1.5984 & 7 & 11.1888 \\
\hline & & & & Total & & & & & 105.4512 \\
\hline
\end{tabular}

TABLE 7: Operating cost of DFLBRMs system.

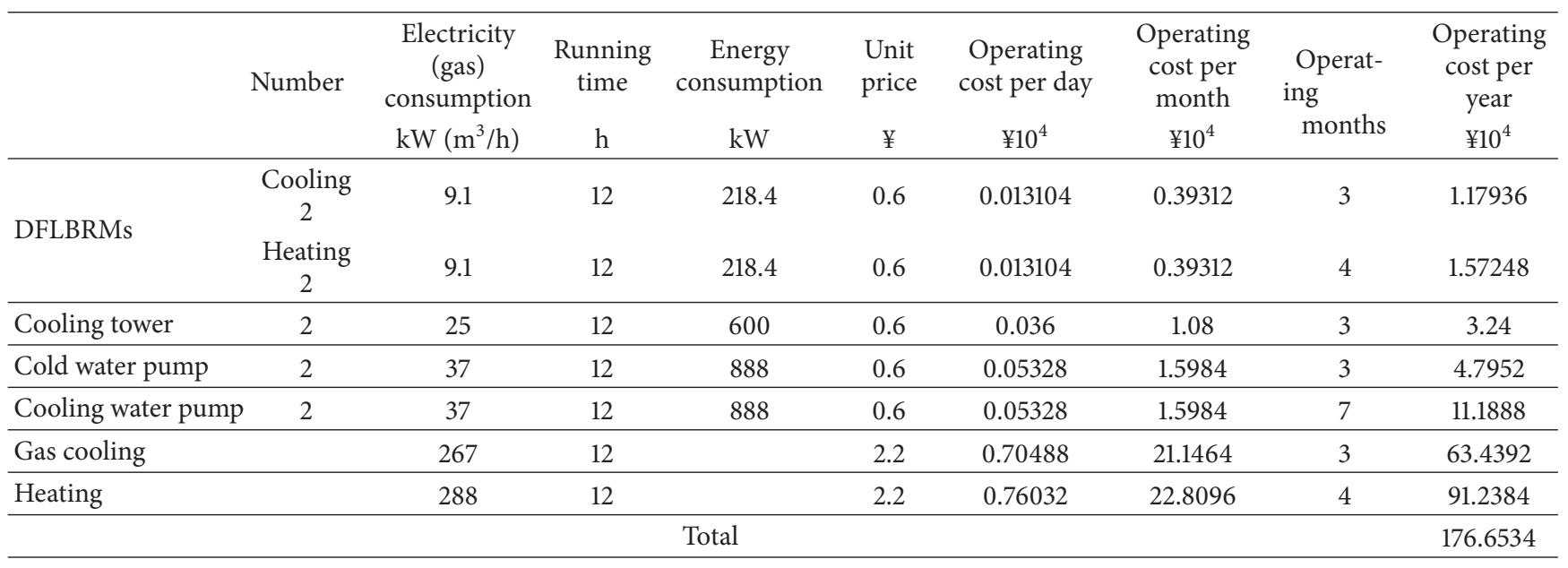

\section{References}

[1] A. Bagdanavicius and N. Jenkins, "Power requirements of ground source heat pumps in a residential area," Applied Energy, vol. 102, pp. 591-600, 2013.

[2] D. Nairen, Ground-Coupled Heat Pump Technology, Higher Education Press, Beijing, China, 1st edition, 2006.

[3] Y. Lu, Y. Liu, X. Li, and Y. Kang, "A new method of drilling long boreholes in low permeability coal by improving its permeability," International Journal of Coal Geology, vol. 84, no. 2, pp. 94-102, 2010.

[4] A. M. Omer, "Ground-source heat pumps systems and applications," Renewable and Sustainable Energy Reviews, vol. 12, no. 2, pp. 344-371, 2008.

[5] B. Sanner, C. Karytsas, D. Mendrinos, and L. Rybach, "Current status of ground source heat pumps and underground thermal energy storage in Europe," Geothermics, vol. 32, no. 4, pp. 579588, 2003.

[6] N. R. Diao, H. Y. Zeng, and Z. H. Fang, "Improvement in modeling of heat transfer in vertical ground heat exchangers," HVAC\&R Research, vol. 10, no. 4, pp. 459-470, 2004.

[7] F. Jun, Diaonairen, and F. Zhaohong, "Analysis of heat disturbance between the pipes of the U-tube geothermal heat exchangers," Journal of Shandong University of Architecture and Engineering, vol. 19, no. 1, pp. 1-4, 2004.
[8] T. V. Bandos, Á. Montero, E. Fernández et al., "Finite linesource model for borehole heat exchangers: effect of vertical temperature variations," Geothermics, vol. 38, no. 2, pp. 263-270, 2009.

[9] H. Yang, P. Cui, and Z. Fang, "Vertical-borehole groundcoupled heat pumps: a review of models and systems," Applied Energy, vol. 87, no. 1, pp. 16-27, 2010.

[10] H. S. Carslaw and J. C. Jeager, Conduction of Heat in Solids, Oxford Press, Oxford, UK, 2nd edition, 1959.

[11] H. Y. Zeng, N. R. Diao, and Z. H. Fang, "A finite line-source model for boreholes in geothermal heat exchangers," Heat Transfer-Asian Research, vol. 31, no. 7, pp. 558-567, 2002.

[12] L. Junhong, Z. wenke, and F. Zhaohong, "Solid cylindrical heat source model for pile ground heat exchangers with spiral coils," Journal of Shandong Jianzhu University, vol. 25, no. 2, pp. 95$100,2010$.

[13] Y. Man, H. Yang, N. Diao, J. Liu, and Z. Fang, "A new model and analytical solutions for borehole and pile ground heat exchangers," International Journal of Heat and Mass Transfer, vol. 53, no. 13-14, pp. 2593-2601, 2010.

[14] P. Cui, X. Li, Y. Man, and Z. Fang, "Heat transfer analysis of pile geothermal heat exchangers with spiral coils," Applied Energy, vol. 88, no. 11, pp. 4113-4119, 2011.

[15] Y. Liang, Z. Jian, Z. Haidong et al., "Preliminary analysis of the methods for ground thermal properties calculations based on 
line heat source model combined with parameter estimation," Refrigeration Air Conditioning \& Electric Power Machinery, vol. 6, pp. 7-11, 2011.

[16] M. Yu and Z. Fang, "A method for the on-site testing of average thermo-physical parameters of underground rock soil," Journal of Engineering for Thermal Energy and Power, vol. 17, no. 5, pp. 489-492, 2002.

[17] Caneta Research, Technical Guide for Engineering of Ground Source Heat Pump, China Building Industry Press, Beijing, China, 2001.

[18] Ministry of Construction of the People's Republic of China, "Technical code for ground source heat pump system," Tech. Rep. GB50366-2005, China Building Industry Press, Beijing, China, 2005.

[19] E. H. Spilker, Ground-Coupled Heat Pump Loop Design Using Thermal Conductivity Testing and the Effect of Different Backfill Materials on Vertical Bore Length, American Society of Heating, Refrigerating and Air-Conditioning Engineers, Atlanta, Ga, USA, 1998.

[20] X. Li, Z. Chen, and J. Zhao, "Simulation and experiment on the thermal performance of U-vertical ground coupled heat exchanger," Applied Thermal Engineering, vol. 26, no. 14-15, pp. 1564-1571, 2006.

[21] H. Wang, C. Qi, H. Du, and J. Gu, "Improved method and case study of thermal response test for borehole heat exchangers of ground source heat pump system," Renewable Energy, vol. 35, no. 3, pp. 727-733, 2010.

[22] P. E. Mikkelsen, "Cement-bentonite grout backfill for borehole instruments," Geotechnical News, vol. 20, no. 4, pp. 38-42, 2002.

[23] S. J. Self, B. V. Reddy, and M. A. Rosen, "Geothermal heat pump systems: status review and comparison with other heating options," Applied Energy, vol. 101, pp. 341-348, 2013. 


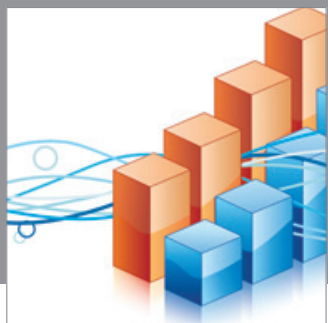

Advances in

Operations Research

mansans

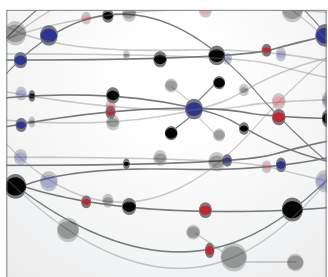

The Scientific World Journal
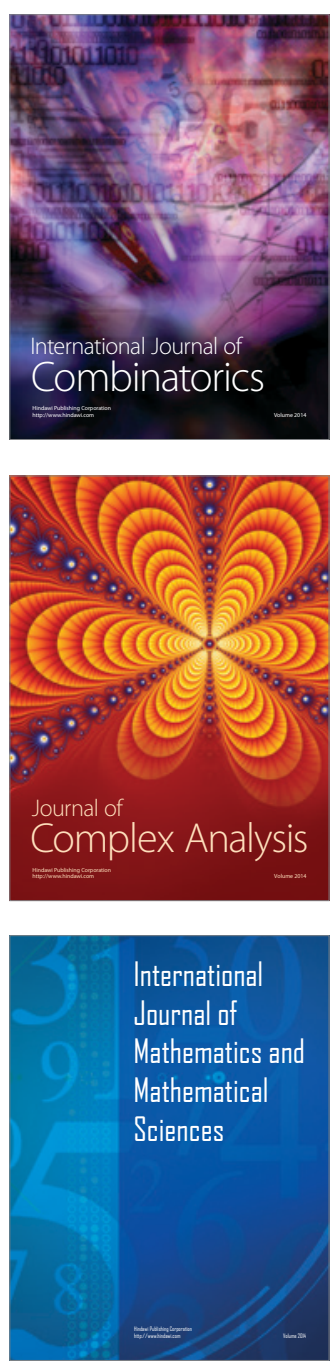
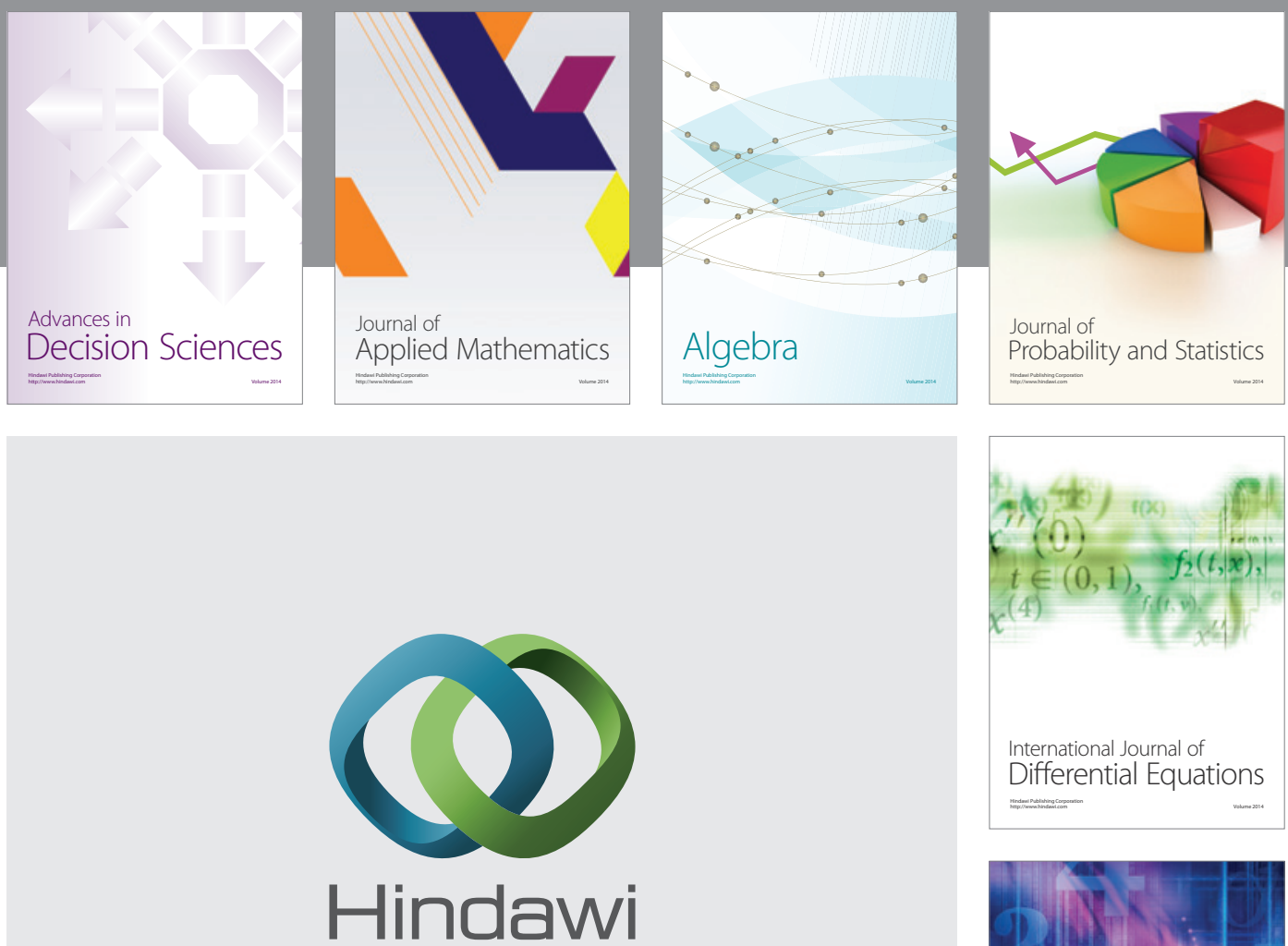

Submit your manuscripts at http://www.hindawi.com
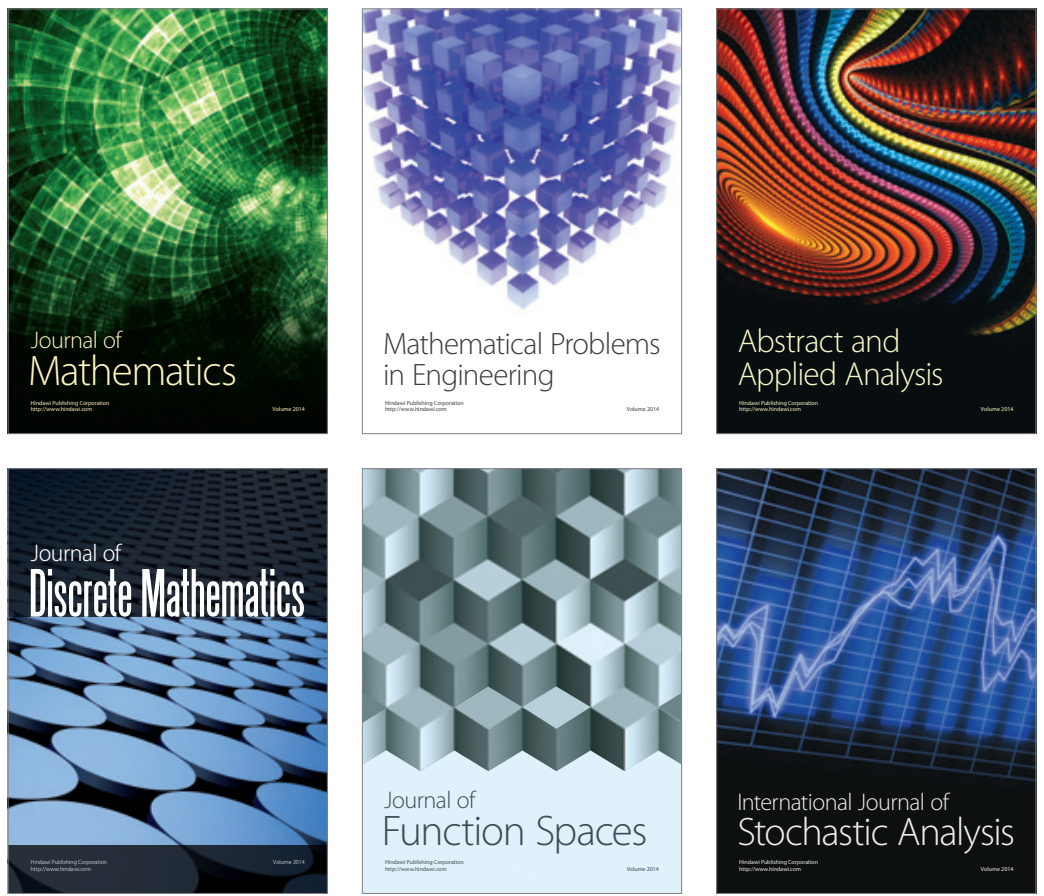

Journal of

Function Spaces

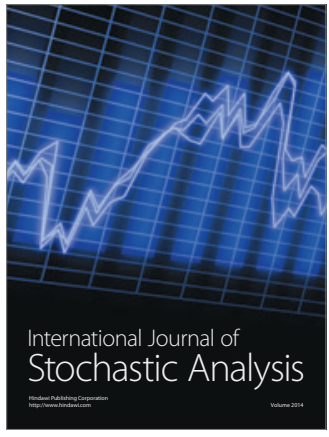

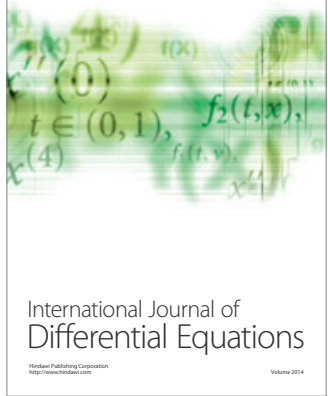
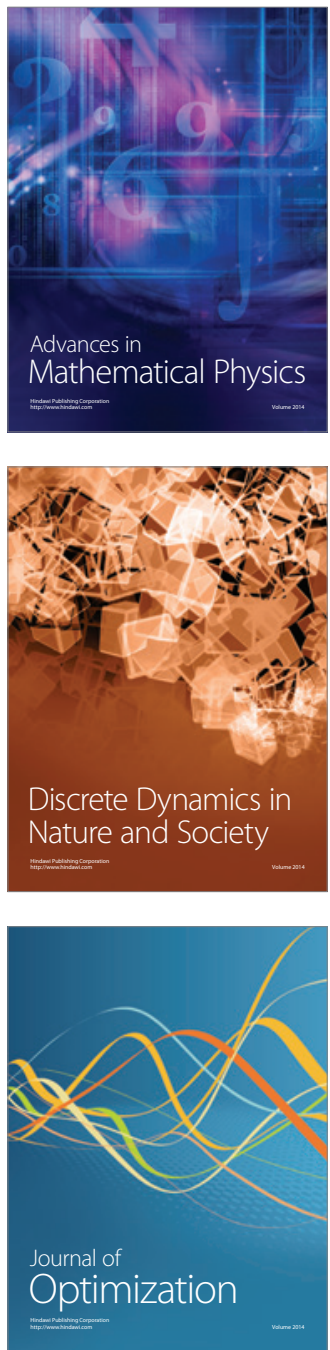